\title{
Feasibility of performing in-scanner exercise testing and assessing myocardial mechanical reserve in normal volunteers and in patients with cardiomyopathy
}

\author{
Joshua Y Cheng ${ }^{1 *}$, Jie J Cao ${ }^{1,2}$, Kathy Halloran ${ }^{1}$ \\ From 17th Annual SCMR Scientific Sessions \\ New Orleans, LA, USA. 16-19 January 2014
}

\section{Background}

While cardiac MRI provides invaluable insight into cardiac structure, function and increasingly hemodynamics, it remains to be challenging to assess cardiac response to exercise stress at peak workload. The objective of this study was to examine the feasibility of in-scanner exercise with a supine ergometer and to assess the myocardial mechanical reserve from rest to stress.

\section{Methods}

We prospectively recruited 13 normal volunteers and 10 stable patients with known ischemic or nonischemic cardiomyopathy. All participants underwent cardiac MRI in a 1.5 T scanner (Siemens Avanto). Prior to exercise participants were fit tested to a modified supine ergometer (Lode, the Netherlands) attached to the scanner table to ensure that the body habitus was appropriate for exercising inside the bore. Exercise began outside the bore with workload set at 25 Watts which was increased every 3 minutes by 25 Watts or adjusted to subjects' tolerance. Participants were slide into the bore while exercising when they reached near maximal capacity or at least $75 \%$ maximally predicted heart rate. Imaging took place while subjects were exercising. Real-time SSFP cine images of the short axis stack covering the whole heart were acquired with free breathing prior to exercise and again at peak exercise. Myocardial circumferential strain was analyzed using Feature Tracking software (CIM V8.1 by Auckland, New Zealand). Endocardial and epicardial

${ }^{1}$ Research, St. Francis Hospital the Heart Center, Greenvale, New York, USA Full list of author information is available at the end of the article contours were drawn in mid ventricle to assess strain of the whole myocardium and of the endocardium.

\section{Results}

All 23 participants successfully completed in-scanner exercise. Heart rate was increased from $62 \mathrm{bpm}$ to $116 \mathrm{bpm}$ for the normal subjects and $61 \mathrm{bpm}$ to $111 \mathrm{bpm}$ for the patients. Systolic blood pressure increased from $115 \mathrm{mmHg}$ to $147 \mathrm{mmHg}$ for normals and $128 \mathrm{mmHg}$ to $171 \mathrm{mmHg}$ for the patients. While both groups demonstrated significant increase in myocardial and endocardial strain $(-16 \pm 3 \%$ to $-20 \pm 3 \%, \mathrm{p}<0.001$ and $-20 \pm 4 \%$ to $-26 \pm 4 \%, \mathrm{p}<0.001$ for normals, $-14 \pm 4 \%$ to $-16 \pm 5 \%, \mathrm{p}<$ 0.001 and $-18 \pm 6 \%$ to $-22 \pm 7 \%, \mathrm{p}<0.001$ for patients, respectively) the increase in myocardial and enocardial strain was much greater in normals (30\% and $32 \%$, respectively) than in patients ( $17 \%$ and $20 \%$, respectively).

\section{Conclusions}

It is feasible to perform in-scanner exercise testing and to assess myocardial response at peak exercise. Our preliminary findings suggest that there is improvement of myocardial mechanical performance attributing to exercise effect for all subjects. However, normal subjects have more favorable myocardial mechanical reserve than patients with cardiomyopathy.

\section{Funding}

St. Francis Research Foundation. 

exercise testing and assessing myocardial mechanical reserve in normal volunteers and in patients with cardiomyopathy. Journal of Cardiovascular Magnetic Resonance 2014 16(Suppl 1):P255.

Submit your next manuscript to BioMed Central and take full advantage of:

- Convenient online submission

- Thorough peer review

- No space constraints or color figure charges

- Immediate publication on acceptance

- Inclusion in PubMed, CAS, Scopus and Google Scholar

- Research which is freely available for redistribution

Submit your manuscript at www.biomedcentral.com/submit
C Biomed Central 